\title{
Association Between Secondary Botulinum Toxin A Treatment Failure in Cosmetic Indication and Anti- Complexing Protein Antibody Production
}

\author{
Rungsima Wanitphakdeedecha • Watsachon Kantaviro • \\ Panittra Suphatsathienkul · Ploypailin Tantrapornpong • \\ Chadakan Yan · Chalermkwan Apinumtham · Yuttana Srinoulprasert (D
}

Received: April 15, 2020 / Published online: May 22, 2020

(c) The Author(s) 2020

\begin{abstract}
Introduction: Botulinum toxin A (BoT/A) treatment failure (BTF) affects patients subjected to repeated BoT/A exposure for cosmetic indications. BoT/A's general formulation contains core BoT/A and complexing proteins. BTF may be caused by antibody-induced treatment failure. Antibodies against core BoT/A can occur; however, anti-complexing protein antibodies have never been demonstrated, and tools for anti-complexing protein antibody detection have not been developed. The aim of this study was to evaluate immune involvement in BoT/Anonresponsive patients.

Methods: Patients suspected of nonresponsiveness to BoT/A for cosmetic indications were recruited. All volunteers were categorized as BoT/A-responsive or BoT/A-tolerant according to frontalis testing with onabotulinumtoxinA
\end{abstract}

Digital Features To view digital features for this article go to https://doi.org/10.6084/m9.figshare.12287270.

R. Wanitphakdeedecha · P. Suphatsathienkul . P. Tantrapornpong · C. Yan · C. Apinumtham Department of Dermatology, Faculty of Medicine Siriraj Hospital, Mahidol University, Bangkok, Thailand

W. Kantaviro · Y. Srinoulprasert ( $\square)$

Department of Immunology, Faculty of Medicine

Siriraj Hospital, Mahidol University, Bangkok,

Thailand

e-mail: yuttana.sri@mahidol.ac.th
(onaA). Twenty-two BoT/A-tolerant volunteers were recruited separately for frontalis testing with incobotulinumtoxinA (incoA). Anti-BoT/A and anti-complexing protein antibodies were quantified by special ELISA using sera from blood sampled before and after frontalis testing. Results: Significantly higher levels of IgG against complexing protein were detected in onaA-tolerant sera but not in onaA-responders, leading to proposals that anti-complexing protein antibodies could cause onaA unresponsiveness. Some onaA-tolerant patients according to frontalis test with incoA were responsive to incoA. Newly developed absorption ELISA confirmed that incoA-responsive sera predominantly contained IgG against complexing proteins, whereas incoA-tolerant sera contained significant levels of IgG against core BoT/A. The presence of anti-complexing protein antibodies higher than $90.75 \%$ in sera of onaA-tolerant patients could respond to incoA. The ELISA technique might be employed as a tool to predict incoA responsiveness. Our frontalis testing after incoA treatment showed that anti-incoA IgG levels were not increased by incoA.

Conclusions: BoT/A-exposed patients may develop antibodies against core botulinum toxin and complexing proteins. Our study is the first to demonstrate that anti-complexing protein antibodies cause BTF. High levels of antibodies against complexing proteins can cause onaA unresponsiveness, although some patients 
were still incoA-responsive. Our developed ELISA to detect anti-complexing protein antibodies can determine whether onaA-tolerant patients respond to incoA without incoA frontalis testing.

Keywords: Antibody; Botulinum toxin A; Complexing protein; ELISA; Secondary botulinum toxin A treatment failure

\section{Key Summary Points}

\section{Why carry out this study?}

Botulinum toxin A (BoT/A) treatment failure (BTF) affects patients subjected to repeated BoT/A (core BoT/A and complexing proteins) exposure for cosmetic indications.

BTF may be caused by antibodies against core botulinum toxin or complexing proteins.

Anti-complexing protein antibodies involved in BTF and how to detect such antibodies have never been demonstrated.

\section{What was learned from the study?}

High levels of anti-complexing protein antibodies associated with BTF in onabotulium toxin (onaB/T)-treated patients.

OnaB/T-tolerant patients with high levels of anti-complexing protein antibody could respond to incobotulinum toxin (incoB/T).

Our newly developed ELISA could be a promising tool to predict whether onaB/Ttolerant patients respond to incoB/T.

\section{INTRODUCTION}

Botulinum toxins (BoTs) have been a principal tool for both clinical and aesthetic physicians. Cosmetic medicine leverages its ability to weaken hyperkinetic lines caused by muscular contractions [1]. BoTs are also used in facial sculpting and shaping, and to correct facial asymmetry [2-12]. US Food and Drug Administration (FDA) approvals have also been granted for botulinum toxin type $\mathrm{A}$ in axillary hyperhidrosis, limb spasticity, chronic migraine and idiopathic overactive bladder [13-21].

Commercially available BoTs in aesthetic medicines include type A and type B subtypes, each of which contains a unique complement of accessory proteins. Type A neurotoxins comprise light and heavy chains, which constitute the core $150-\mathrm{kDa}$ neurotoxin. Type A BoTs (BoT/A) are frequently used and commercially available in preparations including onabotulinumtoxinA (onaA; Botox ${ }^{\circledR}$, Allergan Inc, Irvine, CA, USA), abobotulinumtoxinA (aboA; Dysport ${ }^{\circledR}$, Ipsen Ltd, Slough, Berkshire, UK), and incobotulinumtoxinA (incoA; Xeomin ${ }^{\circledR}$, Merz Pharmaceuticals GmbH, Frankfurt am Main, Hessen, Germany). Of these toxins, incoA is the only product lacking accessory proteins known as complexing proteins [22]. In cosmetic indications, effective treatment with BoT/A requires periodic retreatment, which might trigger immune responses leading to immune resistance and failure to achieve desired outcomes. At least one study has linked the development of immunogenicity and neurotoxin-neutralizing antibodies to complexing proteins and in turn to producing partial or total toxin treatment failure [7, 22]. With complexing protein-containing BoT/A preparations, such failures can occur within 2-3 years of the first treatment and may be caused by BoT/A-neutralizing antibodies produced 1 year following treatment [8]. Shorter treatment intervals, lower toxin doses and using lowantigenicity preparations can minimise the risk of developing immune reactions and antibody production against BoT/A [23-25]. Treatments can be complicated by a patient's or the antigen's capacity to elicit immune responses [24].

Frevert and Dressler postulated that incoA's lack of complexing proteins may reduce both immunogenicity and the risk of antibody production [22]. So far, no tool exists to determine the causes of secondary nonresponse or to confirm the presence of BoT/A-neutralizing 
antibodies. Currently available methods rely on animal models to establish antibody presence, including mouse protection assays using affected patient sera to neutralize toxin and prevent death [26, 27]. However, these tests are impractical for daily, clinical use and are unethical because of their high and often lethal consumption of animals.

We previously investigated the existence of antibodies against BoT/A active sites in sera of secondary BoT/A treatment failure patients [25]. Some serum samples of treatment failure subjects contained low levels of anti-BoT/A active site antibodies, suggesting that BoT/A treatment failure was due to other factors in the sera. One possibility was that such sera contained antibodies against complexing proteins. Therefore, the aim of the present study was to investigate the existence of anti-complexing protein antibodies in the sera of BoT/A treatment failure patients. We thus developed a technique to detect anti-complexing protein antibodies.

\section{METHODS}

\section{Volunteers}

This was a prospective cohort study performed at a single centre in Thailand. Seventy-four healthy subjects aged 18 years or older, who were suspected of BoT/A tolerance, were enrolled. Frontalis testing with onaA $\left(\right.$ Botox $^{\circledR}$ ) was performed on all subjects to confirm the diagnosis of onaA-tolerant (onaA-T). Thirty-five $(47.3 \%)$ subjects responded to onaA (onaA-responsive, onaA-R) while 39 (52.7\%) subjects did not respond (onaA-T). All 39 onaA-T subjects were asked to repeat frontalis testing with incoA $\left(\right.$ Xeomin $\left.^{\circledR}\right)$. Twenty-two onaA-T subjects agreed to frontalis testing with incoA as illustrated in Fig. 1. The average interval between frontalis testing with onaA or incoA was 7.52 months. These 22 subjects were divided into two groups based on the results of incoA frontalis testing: onaA-tolerant with incoA-responsive (onaA-T with incoA-R) and onaA-tolerant with incoAtolerant (onaA-T with incoA-T). Blood samples were collected immediately before and 2 weeks after frontalis tests were performed with either
onaA or incoA (Fig. 1). Absorption ELISA to detect anti-non-BoT/A antibodies and inhibition ELISA to detect the anti-active sites of BoT/ A antibodies were conducted on the second and third collections of blood samples. This prospective analytic study was approved by the ethical committee, Faculty of Medicine, Siriraj Hospital, Mahidol University (COA No. Si 087/2020). All procedures performed in studies involving human participants were in accordance with the institutional research committee and with the 1964 Helsinki Declaration and its later amendments or comparable ethical standards. Informed consent was obtained from all individual participants included in the study.

\section{Frontalis Test}

The frontalis muscle was injected unilaterally with onaA in all patients and onaA tolerance was assessed as described previously [28]. Briefly, 20 units of either onaA or incoA was injected at a location $3 \mathrm{~cm}$ above the lateral and medial canthus of one eye but not into the contralateral eye area. The patient's ability to raise both eyebrows was analysed 2 weeks postinjection. Asymmetric muscular activity proved BoT/A efficacy and patients were included or excluded on the basis of these outcomes.

\section{Blood Sample Collection}

Ten millilitres of blood was collected from each subject and centrifuged at $1000 \mathrm{rpm}$ for $10 \mathrm{~min}$ at room temperature to separate sera from solid components. Sera was collected and stored at $-20^{\circ} \mathrm{C}$ until use.

\section{Absorption ELISA to Detect Anti-Non-BoT/ A Antibodies}

Ninety-six-well plates were labelled either as "absorption" or "working" plates. An incoA solution $(0.028$ unit $/ \mathrm{ml})$ was used to coat selected wells in absorption plates at $50 \mu \mathrm{l} /$ well, while selected working plate wells were coated with $0.051 \mathrm{unit} / \mathrm{ml}$ of onaA solution. Absorption was performed in incoA-coated plates by washing wells with $0.05 \%$ Tween-20 in 


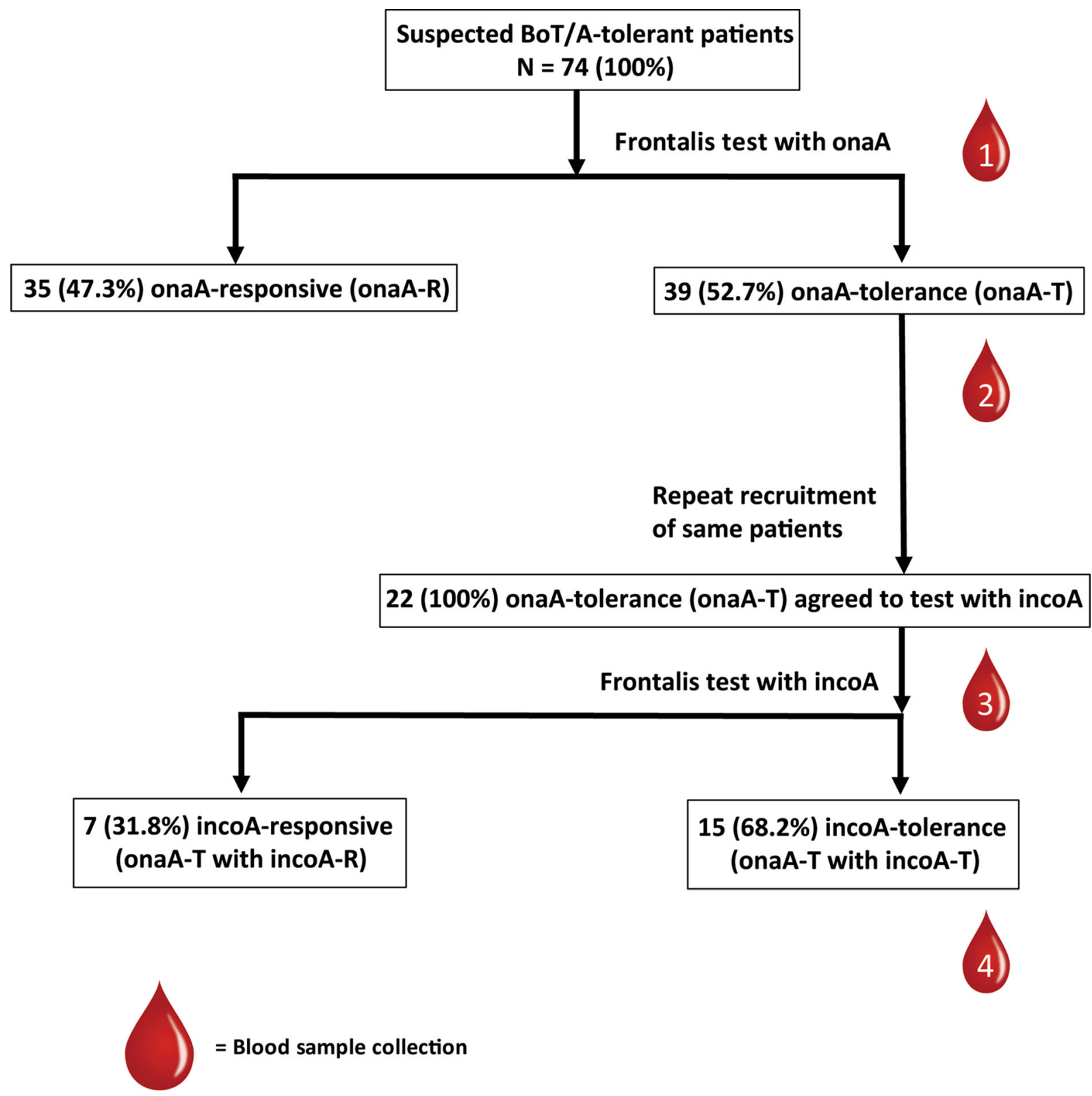

Fig. 1 Schematic plan. A patient suspected of BoT/A nonresponsiveness was recruited for frontalis testing and blood collection thereafter. Blood was sampled four times and subjected to ELISA. The first and third collections

phosphate buffered saline (PBST) and blocking with $1 \%$ bovine serum albumin (BSA) in PBS for $1 \mathrm{~h}$ at $37^{\circ} \mathrm{C}$ in a humidified chamber. After washing, $100 \mu \mathrm{l} /$ well of 1:50 diluted patient serum was added and plates were placed in a humidified shaking incubator at $37^{\circ} \mathrm{C}$ for $1 \mathrm{~h}$. Approximately $100 \mu \mathrm{l}$ of absorbed serum was were performed prior to frontalis testing, while the second and fourth samples were collected 2 weeks after frontalis testing. Blood droplet illustrations represent blood sample collection events

transferred to other incoA-coated wells and the absorption step was repeated twice. Following absorption, approximately $100 \mu \mathrm{l}$ of absorbed sample was transferred to the working plate (onaA-coated and blocked with 1\% BSA) and incubated at $4{ }^{\circ} \mathrm{C}$ for $2 \mathrm{~h}$ in a humidified chamber. In parallel, $100 \mu$ l of freshly diluted 
(1:50) un-absorbed serum samples was added to adjacent, matched wells. After washing, freshly prepared, HRP-conjugated rabbit anti-hIgG antibody solution was added and incubated at $37^{\circ} \mathrm{C}$ for $1 \mathrm{~h}$. After the wells were washed five times, TMB was added to each well and colour developed for $10 \mathrm{~min}$ in the dark at room temperature. Colour development was stopped with $1 \mathrm{~N} \mathrm{HCl}$ and the optical density of each well was measured at $450 \mathrm{~nm}$.

\section{Inhibition ELISA to Detect Anti-BoT/A Active Site Antibodies}

The ELISA plate was coated with incoA and blocked with a mixture of three mouse monoclonal antibodies prior to incubating with 1:50 diluted sera. We developed and previously published this method of detecting human IgG against the active sites of BoT/A [25].

\section{Statistical Analysis}

Results were analysed by either parametric or non-parametric paired tests, where appropriate. The differences between the ELISA values for the non-absorbed and absorbed samples were analysed and used to calculate the percentage of anti-complexing protein antibody using the formula:

\section{RESULTS}

\section{OnaA-T Patient Demographics and Clinical Data}

The demographic data of 22 onaA-T is shown in Table 1. Seven (31.8\%) onaA-T subjects, six women and one man with a median age of 35 years, were incoA-responsive during frontalis testing and were categorized as onaA-T with incoA-R. Fifteen $(68.2 \%)$ onaA-T subjects, 14 women and one man with a median age of 33 years, were incoA-unresponsive and were categorized as onaA-T with incoA-T. When comparing between incoA-T and incoA-R groups, the number of BoT/A injections and total doses for cosmetic indications were significantly different. Tolerant patients had more injections and higher doses per injection and total cumulative dose prior to the study.

\section{Different Quantities of Anti-Complexing Proteins Between OnaA-Responsive and OnaA-Tolerant Patients}

Sera from all patients tested with onaA (both onaA-R and onaA-T; blood sample 2) were subjected to absorption ELISA. Total sera (un-absorbed) were suspected of containing antibodies against core botulinum toxin and complexing

$$
\begin{aligned}
& {\left[\begin{array}{r}
1-(\text { the numerical difference between the values for non-absorbed and absorbed samples } \\
\text { divided by the numerical values for non-absorbed sample }
\end{array}\right)} \\
& \times 100 \%
\end{aligned}
$$

Threshold values were obtained by applying receiver operating characteristic (ROC) data analysis. Statistical significance was reached when $p<0.05$. proteins whereas absorbed sera, having been depleted of antibodies specific to core botulinum toxin, were suspected of containing only antibodies against complexing proteins. After absorption, differences in hIgG were observed between sera from onaA-responsive and onaAtolerant patients. OnaA-responsive sera hIgG 
Table 1 Demographic data of onaA-tolerant patients

\begin{tabular}{|c|c|c|c|c|c|c|c|c|}
\hline \multirow[t]{2}{*}{ Group } & \multirow{2}{*}{$\begin{array}{l}\text { Median } \\
\text { age } \\
\text { (years) }\end{array}$} & \multicolumn{2}{|l|}{ Gender } & \multirow{2}{*}{$\begin{array}{l}\text { Median } \\
\text { duration } \\
\text { (years) }\end{array}$} & \multirow{2}{*}{$\begin{array}{l}\text { Median } \\
\text { dose/visit } \\
\text { (units) }\end{array}$} & \multirow{2}{*}{$\begin{array}{l}\text { Median } \\
\text { number of } \\
\text { injections }\end{array}$} & \multirow{2}{*}{$\begin{array}{l}\text { Median } \\
\text { interval } \\
\text { (months) }\end{array}$} & \multirow{2}{*}{$\begin{array}{l}\text { Median } \\
\text { total dose } \\
\text { (units) }\end{array}$} \\
\hline & & $\begin{array}{l}\text { Female, } \\
n(\%)\end{array}$ & $\begin{array}{l}\text { Male, } \\
n(\%)\end{array}$ & & & & & \\
\hline All & 34 & $25(73.5)$ & $9(26.5)$ & - & - & - & - & - \\
\hline $\begin{array}{l}\text { IncoA- } \\
\text { responsive } \\
\text { patients } \\
(n=7)\end{array}$ & 35 & $6(85.70)$ & $1(14.30)$ & 7 & 70 & 12 & 5 & 800 \\
\hline $\begin{array}{l}\text { IncoA-tolerant } \\
\text { patients } \\
(n=15)\end{array}$ & 33 & $\begin{array}{l}14 \\
\quad(03.30)\end{array}$ & $1(6.70)$ & 7 & 100 & 16 & 5 & 1600 \\
\hline$p$ value & & & & 0.731 & 0.07 & $<0.05$ & 0.267 & $<0.01$ \\
\hline
\end{tabular}

levels were significantly decreased $(p<0.05)$ after absorption (Fig. 2a), whereas onaA-tolerant sera hIgG levels were not significantly changed ( $p>0.05)$ (Fig. 2b). Therefore, antibodies persisting after absorption in onaA-tolerant sera may be hIgG that are reactive to complexing proteins and suggested that onaAtolerant patients are affected by antibodies against complexing proteins.

\section{OnaA-T with IncoA-R Group}

On the basis of the present results, we questioned whether onaA-tolerant patients would respond to pure BoT/A. Therefore, the frontalis test was repeated with incoA on 22 of the original 39 onaA-tolerant patients as illustrated in Fig. 1. Approximately $31 \%$ (7 of 22 patients) of patients responded to incoA, supporting our hypothesis and suggesting that incoA tolerance might arise as a result of factors unrelated to incoA.

\section{Sera of OnaA-T with IncoA-R Patients Contained Significant Levels of Anti- Complexing Protein Antibodies}

As proof of concept that onaA-tolerant patients could still respond to incoA because the observed interference was only due to anti- complexing protein antibodies reacting against onaA, absorption ELISA was repeated on serum samples from the 22 onaA-T patients. Following absorption, differences were observed in the detected hIgG levels between incoA-responsive (Fig. 3b) and incoA-tolerant patients (Fig. 3a). These findings were reversely different from the detected hIgG levels from onaA-responsive and onaA-tolerant patients as shown in Fig. 2. After absorption, all sera from incoA-responsive patients contained no significant change in levels of hIgG $(p>0.05)$, whereas hIgG levels in incoA-tolerant sera were significantly decreased $(p<0.05)$. These findings suggest that incoAresponsive sera could contain impactful levels of hIgG that target complexing proteins while incoA-tolerant sera contains fewer anti-complexing protein antibodies.

\section{Predictive Cut-Off Threshold for OnaA-T with IncoA-R Patients}

According to our absorption ELISA results, if hIgG levels in absorbed sera were comparable to those in un-absorbed sera, such sera may contain predominantly complexing protein-specific hIgG. Conversely, if hIgG levels in absorbed sera were lower than those in un-absorbed sera, such sera may contain predominantly hIgGs against the core botulinum toxin and complexing 

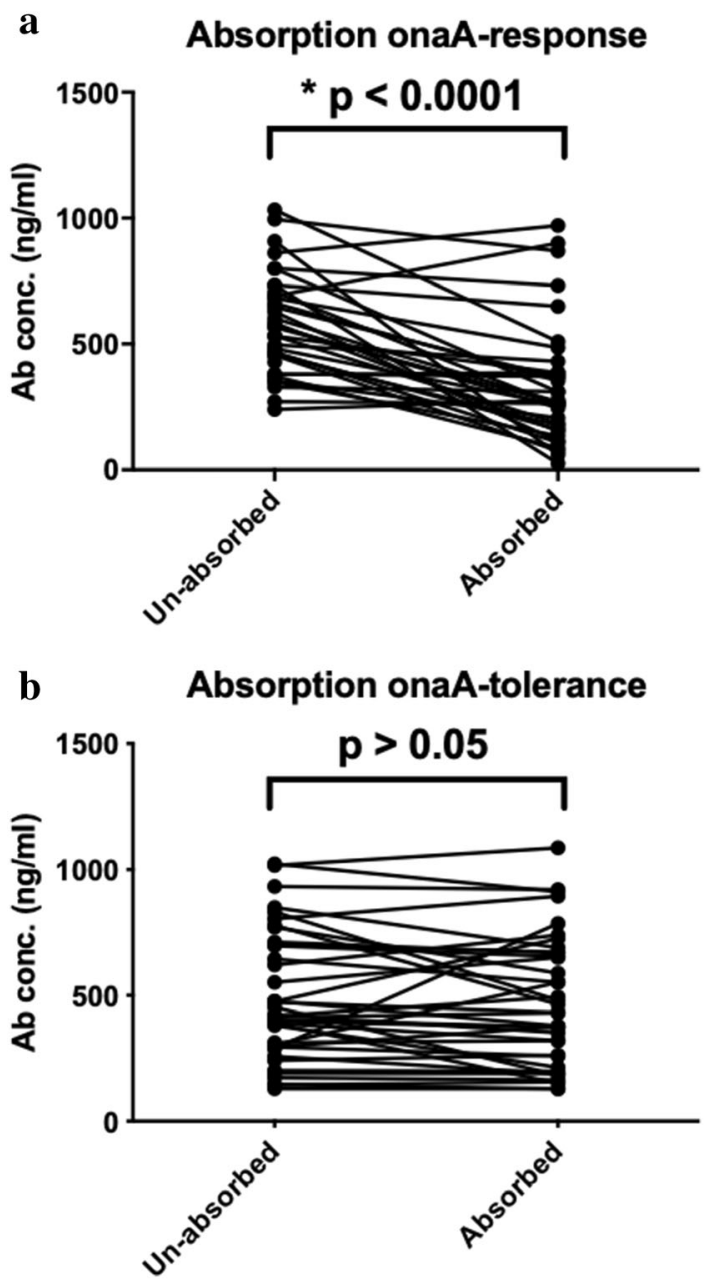

Fig. 2 Absorption ELISA with onaA-responsive and onaA-tolerant sera. Sera from the second blood collection were subjected to absorption ELISA. 'Un-absorbed' denotes whole sera that were not depleted of antibodies, while 'absorbed' denotes sera depleted of antibodies against incoA prior to anti-complexing protein hIgG detection by ELISA. Match-paired line graphs represent levels of hIgG against BoT/A and complexing proteins (un-absorbed) or only complexing proteins (absorbed) from onaA-responsive volunteers (a) and onaA-tolerant (b) patients. *Statistical significance at $p$ value $<0.05$

proteins. Therefore, we interpreted the subtractive values of hIgG in the un-absorbed and absorbed sera as the quantity of hIgG against complexing proteins in the sera. To normalize the differences in basal levels, decreasing values were converted into percentages of reduction and analysed by ROC analysis (Fig. 4). The highest value of Youden's index at 180 was
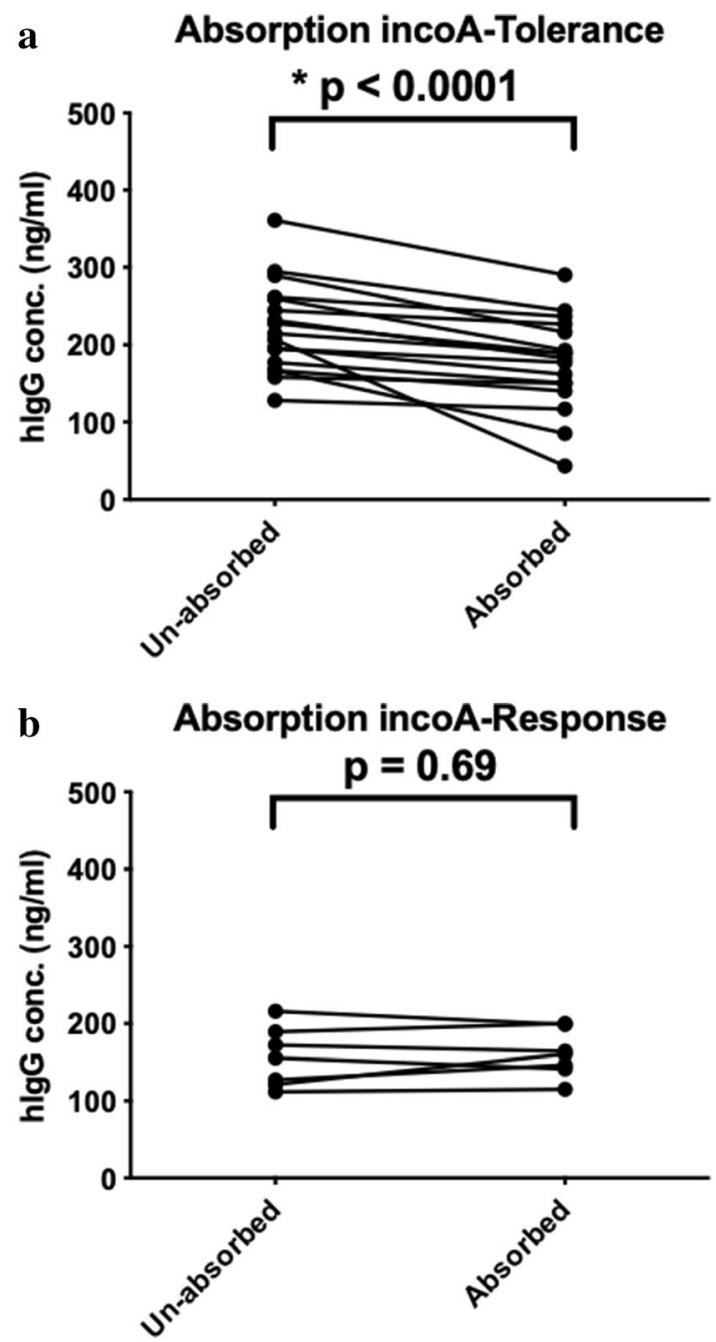

Fig. 3 Absorption ELISA with incoA-tolerant and incoAresponsive sera. Sera from the third blood collection were subjected to absorption ELISA. 'Un-absorbed' denotes whole sera that were not depleted of antibodies, while 'absorbed' denotes patient sera that were depleted of antibodies against incoA before detecting anti-complexing protein hIgG by ELISA. Match-paired line graphs represent levels of $\mathrm{hIgG}$ against BoT/A and complexing proteins (un-absorbed) or only complexing proteins (absorbed) from incoA-tolerant patients (a) and incoAresponsive volunteers (b). ${ }^{*}$ Statistical significance at $p$ value $<0.05$

chosen to achieve an optimal cut-off value at $90.75 \%$ (Table 2). Consequently, if the percentage of hIgG specific to complexing proteins (in absorbed serum) was higher than $90 \%$ of the percentage of hIgG against whole BoT/A (in un- 


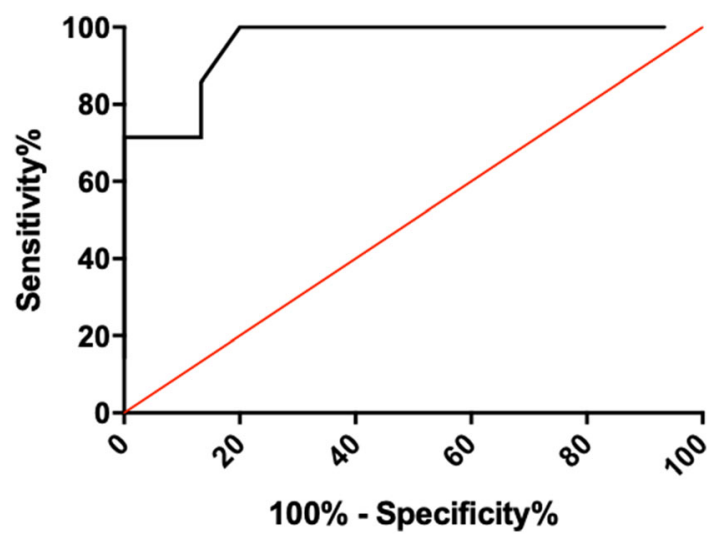

Fig. 4 ROC curve demonstrates percentage of reduction in hIgG levels and incoA outcomes. Cut-off points for percentage of reduction in hIgG corresponded to sensitivity, specificity and Youden's index and are shown in Table 2

absorbed serum), the affected patient may respond to incoA with a toxin sensitivity of $100 \%$ and specificity of $80 \%$.

\section{OnaA-T with IncoA-R Patients Were Not} Affected by Anti-Active Sites of Botulinum Toxin

We also hypothesized that patients who were both onaA-tolerant and incoA-responsive arose as a consequence of having antibodies against complexing proteins, but not antibodies against BoT/A active sites. Using an inhibition ELISA developed by our group [25], we found no significant difference in hIgG levels against core botulinum toxin $(p>0.05)$ in either incoA-responsive or incoA-tolerant sera (Fig. 5) even when all three BoT/A active sites were specifically blocked with mouse monoclonal antibodies beforehand. These results indicated that hIgG against all three BoT/A active sites did not affect incoA function, since changes in hIgG levels were insignificant and not associated with the outcomes of incoA frontalis testing.

\section{IncoA Did Not Provoke Anti-Core Botulinum Toxin Antibody}

Using our ELISA test [25], we analysed sera from patients before and after incoA injection for
Table 2 Cut-off threshold for percentage of reduction, sensitivity, specificity and Youden's index to predict incoA responsiveness

\begin{tabular}{llll}
\hline Cut-off & Sensitivity & Specificity & Youden's index \\
\hline$>35.95$ & 100 & 6.667 & 106.67 \\
$>62.70$ & 100 & 13.33 & 113.33 \\
$>74.65$ & 100 & 20 & 120.00 \\
$>76.85$ & 100 & 26.67 & 126.67 \\
$>79.60$ & 100 & 33.33 & 133.33 \\
$>81.55$ & 100 & 40 & 140.00 \\
$>82.80$ & 100 & 46.67 & 146.67 \\
$>83.50$ & 100 & 53.33 & 153.33 \\
$>84.60$ & 100 & 60 & 160.00 \\
$>86.55$ & 100 & 66.67 & 166.67 \\
$>89.30$ & 100 & 73.33 & 173.33 \\
$>90.75$ & 100 & 80 & 180.00 \\
$>91.45$ & 85.71 & 86.67 & 172.38 \\
$>92.35$ & 71.43 & 86.67 & 158.10 \\
$>93.80$ & 71.43 & 93.33 & 164.76 \\
$>95.15$ & 71.43 & 100 & 171.43 \\
$>99.05$ & 57.14 & 100 & 157.14 \\
$>104.1$ & 42.86 & 100 & 142.86 \\
$>110.3$ & 28.57 & 100 & 128.57 \\
$>123.8$ & 14.29 & 100 & 114.29 \\
\hline & & &
\end{tabular}

frontalis testing (blood samples 3 and 4) to quantify hIgG levels against botulinum toxin and determine if incoA provoked antibody responses. Levels of hIgG against core botulinum toxin were not significantly different between sera of patients before and after incoA frontalis testing ( $p>0.05$; Fig. 6a). Match-pairing graphs also confirmed that hIgG levels were not significantly changed between both sera $(p>0.05$; Fig. $6 \mathrm{~b})$, suggesting that incoA does not cause or increase immunogenicity in patients previously exposed to BoT/A. 

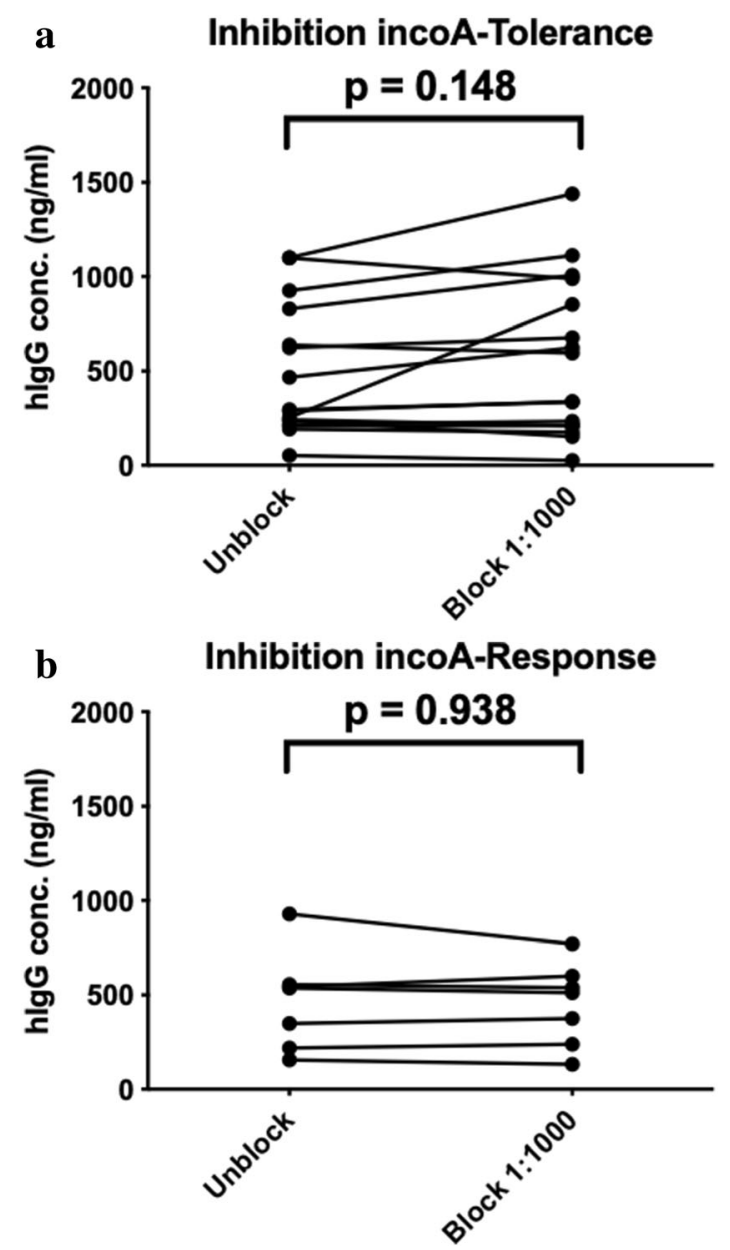

Fig. 5 Inhibition ELISA to detect antibodies against BoT/A active sites. Sera from the third blood sample collection were subjected to inhibition ELISA. Matchpaired line graphs represent levels of hIgG against active sites of BoT/A in sera from incoA-tolerant patients (a) and incoA-responsive patients (b) before ('Unblock') and after ('Block 1:1000') active site blockage by mouse monoclonal antibodies. Statistical significance at $p$ value $<0.05$

\section{DISCUSSION}

Secondary treatment failures after botulinum toxin treatments are caused by clinical factors, patients' requests for shorter injection intervals and more customized treatments, and the use of higher doses and increased injection frequencies [29]. Analysis of clinical data revealed that high toxin doses per visit and cumulative doses are associated with secondary BoT/A treatment
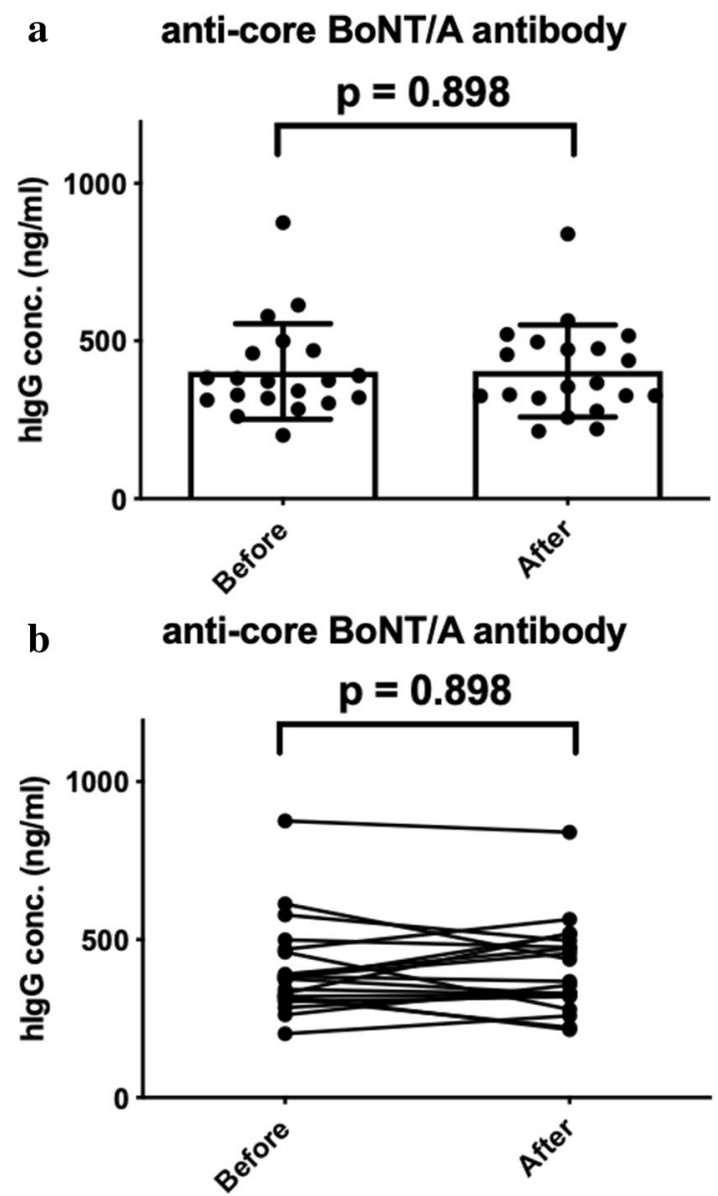

Fig. 6 Levels of anti-core BoT/A antibodies in sera before and after incoA frontalis testing. Antibodies against core $\mathrm{BoT} / \mathrm{A}$ in sera from the third and fourth blood sample collections were quantified by ELISA using plates precoated with incoA. Match-paired linear plot (a) and bar graphs with overlapping data points (b) were generated from the same dataset. The match-paired linear plot suggested no significant change in levels of hIgG against incoA before and after incoA induction, as shown in the bar graphs. Statistical significance at $p$ value $<0.05$

failure even when the highly pure incoA preparation was used. This finding was similar to our previous report that botulinum toxin tolerance could be induced by, and correlated with, an increasing quantity of injected BoT/A [25]. Interestingly, more frequent BoT/A exposure corelated with BoT/A tolerance. We also noted that some patients could still respond to non-toxin-associated proteins in BoT/A formulations. As such, the demand for BoT/A with 
minimal immunogenicity or antigenicity endures and may be suitably filled by commercial preparations such as incoA, which lacks complexing proteins [30]. To date, secondary treatment failure due to incoA has not been detected in toxin-naïve patients.

OnaA-responsive sera also contained hIgG against both core BoT/A and complexing proteins (Fig. 2a). Following depletion of anti-core BoT/A antibody, levels of hIgG against complexing proteins in some patients were lower than levels of hIgG against both BoT/A and complexing proteins (in un-absorbed sera). This is the first documented observation of the existence of anti-complexing protein antibodies determined by our newly developed absorption ELISA technique. These results suggested that there may be fewer anti-complexing protein hIgG than anti-core BoT/A hIgG in the sera of onaA-responsive patients. Conversely, levels of hIgG in some onaA-tolerant sera did not decrease significantly after absorption, suggesting that some of the hIgG in these sera were targeting anti-complexing proteins. This finding raised a possibility that onaA treatment failure might be caused by antibodies induced against onaA. This possibility was raised during an evaluation of neutralizing antibodies in patients with secondary treatment failure following use of complexing protein-free BoT/A preparations [30]. Over $80 \%$ of patients had decreased neutralizing antibody titres and over $60 \%$ of these patients experienced a decrease in titres to the limit of detection.

Compared to the $150-\mathrm{kDa}$ core neurotoxin, the complex-containing $900-\mathrm{kDa}$ unit is a substantial foreign protein load and highly possible immune target. Thus, complexing proteins theoretically increase the risk of antibody production against themselves and their associated neurotoxin. Although the application of BoT/A at lower doses or with reduced protein content in aesthetic medicine may reduce the risk of neutralizing antibody development, recent reports suggest that they did not completely prevent the development of immunogenicity $[31,32]$. As such, the presence of anti-complexing protein hIgG could induce BoT/A treatment failure and the absence of complexing proteins in incoA may be clinically beneficial for physicians wishing to avoid antigenicity, as has been demonstrated in animal studies [33-35].

As proof of concept that anti-complexing protein antibodies interfere with onaA function, we challenged onaA-T patients with incoA. Approximately $30 \%$ of onaA-T patients could respond to incoA and their sera contained the most hIgG against complexing proteins (Fig. 3b). Even though high levels of anti-complexing protein antibody in incoA-responsive patients were detected, these antibodies did not affect incoA function. This study is the first to present scientific evidence indicating that secondary BoT/A treatment failure could be caused by anti-complexing protein antibodies. We also investigated why incoA-tolerant patients were nonresponsive to complexing protein-free BoT/ A. Previously, we reported that onaA tolerance was associated with the existence of antibodies to the BoT/A active sites. We performed inhibition ELISA and showed that both incoA-tolerant and incoA-responsive sera did not contain significant levels of hIgG against all three BoT/A active sites. Therefore, incoA-tolerant patients may fail incoA treatment owing to the existence of antibodies against core BoT/A apart from active sites and other unknown factors unrelated to incoA. With this finding, we hypothesized that the low immunogenicity of incoA may provoke immune responses and production of significant levels of hIgG against the core BoT/A. However, we observed an insignificant change in levels of hIgG against the core BoT/A between sera obtained before and after incoA administration (Fig. 6a), suggesting that incoA did not provoke immune responses or significant antibody production against the core BoT/A. This was consistent with previous reports that repeated injections of incoA did not result in the development of any neutralizing antibodies to incoA $[36,37]$.

On the basis of our absorption ELISA results (Fig. 3), we analysed the percentage of anticomplexing protein antibodies in incoA-tolerant sera and incoA-responsive sera with ROC to determine cut-off thresholds for this evaluation. ROC analysis revealed an excellent curve and suggested that a percentage of anti-complexing protein antibodies of $90.75 \%$ was predictive for 


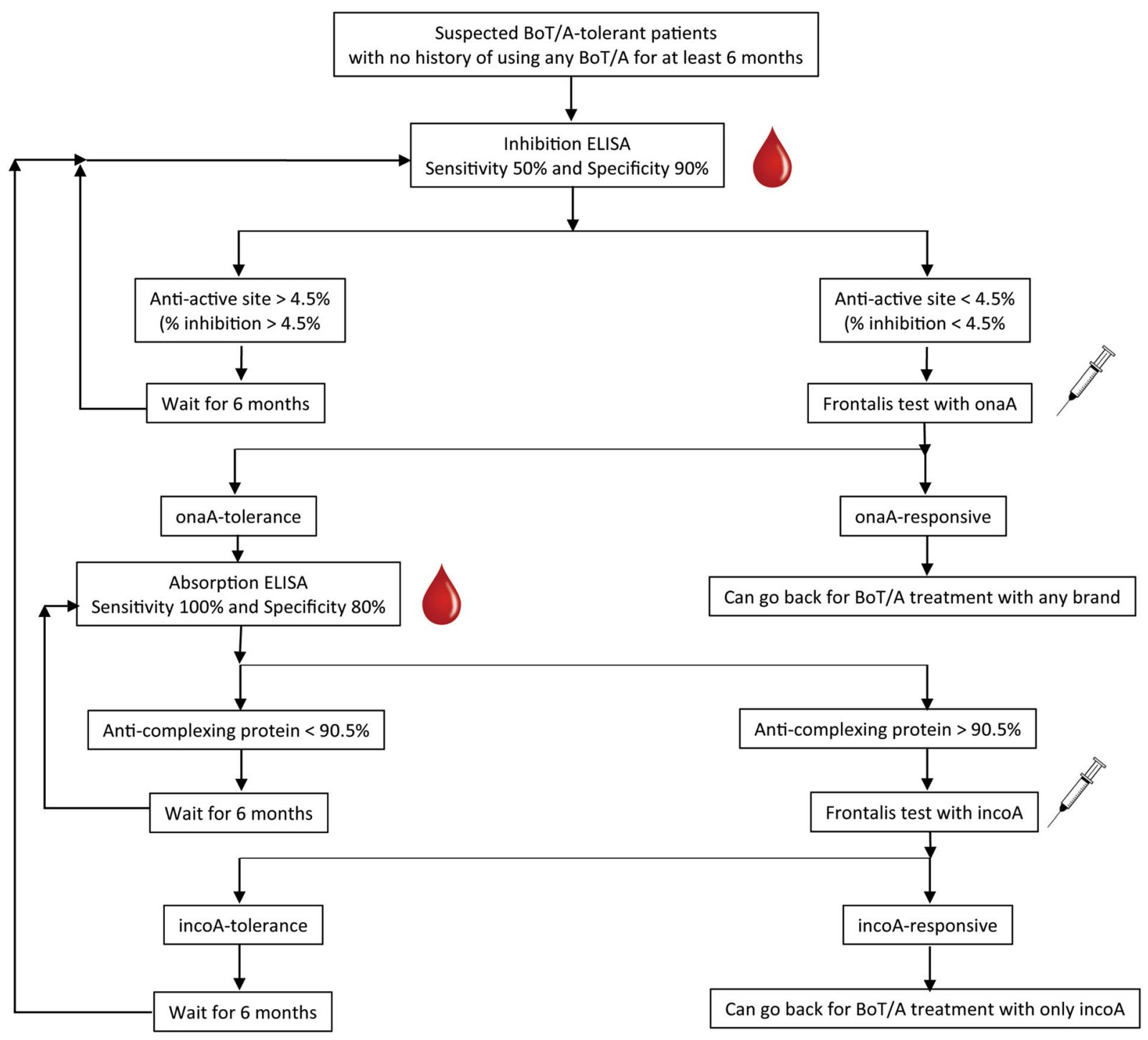

Fig. 7 Proposed treatment protocol for patients suspected of BoT/A tolerance. In patients suspected of BoT/A tolerance, we recommend completely ceasing injections of any brand of BoT/A for at least 6 months and performing diagnostic evaluations using both inhibition and

patients who respond to incoA, with an excellent sensitivity of $100 \%$ and very good specificity (80\%). This level of sensitivity and specificity suggests that our absorption ELISA technique may be useful for predicting the responsiveness of onaA-tolerant patients to incoA. It may also be indispensable for aesthetic physicians and patients when discussing and choosing the type of BoT/A required for further absorption ELISA. Blood droplet illustrations represent blood sample collection events for ELISA investigations and syringe illustrations represent frontalis testing events with various BoT/A formulations

treatment in the setting of onaA treatment failures.

Therefore, we propose a protocol and treatment approach for patients suspected of BoT/A tolerance: instead of switching BoT/A brands or injecting the same type or brand of BoT/A repeatedly, we recommend that all doctors stop injecting BoT/A for at least 6 months and instead use both inhibition and absorption 
ELISA, as shown in Fig. 7, to prevent further antibody production or immune responses against BoT/A.

Lastly, there are a few limitations to our study. As a result of the prevalence of BTF being low, collection of prospective BTF cases in the future is needed to support these results. In addition, validation of our newly developed absorption ELISA is still required with new cohorts of BTF and botulinum toxin responsive groups.

\section{CONCLUSION}

The results of this study demonstrated that BoT/ A-exposed patients could produce antibodies against core botulinum toxin and complexing proteins. Levels of anti-complexing protein antibodies were quantified by our newly developed ELISA and their levels associated with BTF were firstly demonstrated. Our study suggested that onaA-unresponsive patients produced high levels of antibodies against complexing proteins that could respond to incoA. Our ELISA technique might be employed as a tool to predict whether onaA-tolerant patients respond to incoA without incoA frontalis testing.

\section{ACKNOWLEDGEMENTS}

We gratefully thank all the donors that participated in this project. The authors wish to thank Ms. Phassara Klamsawat, Ms. Phonsuk Yamlexnoi, Ms. Tunsuda Tansit, and Mr. Panyawat Wongjaruwat for their assistance in recruiting subjects and database management. Critical reading and grammatical correction by Shawna Tan were also appreciated.

Funding. This research project and the journals rapid service fee were supported by the Faculty of Medicine Siriraj Hospital, Mahidol University.

Authorship. All named authors meet the International Committee of Medical Journal Editors (ICMJE) criteria for authorship for this article, take responsibility for the integrity of the work as a whole, and have given their approval for this version to be published.

Authorship Contributions. RW and YS had full access to all data in the study and take responsibility for the integrity of data and the accuracy of the data analysis. Study concept and whole design: YS and RW. Laboratory design: WK and YS. Acquisition of data: RW, WK, PS, PT, CY, CA, and YS. Analysis and interpretation of data: RW, WK, PS and YS. Drafting of the manuscript: YS and RW. Critical revision of the manuscript for important intellectual content: YS and RW. Statistical analysis: WK and YS.

Disclosures. Rungsima Wanitphakdeedecha, Watsachon Kantaviro, Panittra Suphatsathienkul, Ploypailin Tantrapornpon, Chadakan Yan, Chalermkwan Apinumtham, and Yuttana Srinoulprasert have nothing to disclose. The funding sponsors had no role in the design of the study; in the collection, analysis and interpretation of the data; in the writing of the manuscript or in the decision to publish the results.

Compliance with Ethics Guidelines. This prospective analytic study was approved by the ethical committee, Faculty of Medicine, Siriraj Hospital, Mahidol University (COA No. Si 087/2020). All procedures performed in studies involving human participants were in accordance with the institutional research committee and with the 1964 Helsinki Declaration and its later amendments or comparable ethical standards. Informed consent was obtained from all individual participants included in the study.

Data Availability. The datasets generated during and/or analyzed during the current study are available from the corresponding author on reasonable request.

Open Access. This article is licensed under a Creative Commons Attribution-NonCommercial 4.0 International License, which permits any non-commercial use, sharing, adaptation, distribution and reproduction in any medium or format, as long as you give appropriate credit to the original author(s) and the source, provide 
a link to the Creative Commons licence, and indicate if changes were made. The images or other third party material in this article are included in the article's Creative Commons licence, unless indicated otherwise in a credit line to the material. If material is not included in the article's Creative Commons licence and your intended use is not permitted by statutory regulation or exceeds the permitted use, you will need to obtain permission directly from the copyright holder. To view a copy of this licence, visit http://creativecommons.org/licenses/by$\mathrm{nc} / 4.0 /$.

\section{REFERENCES}

1. Anido J, Arenas D, Arruabarrena C, et al. Tailored botulinum toxin type A injections in aesthetic medicine: consensus panel recommendations for treating the forehead based on individual facial anatomy and muscle tone. Clin Cosmet Investig Dermatol. 2017;10:413-21.

2. Armstrong MW, Mountain RE, Murray JA. Treatment of facial synkinesis and facial asymmetry with botulinum toxin type A following facial nerve palsy. Clin Otolaryngol Allied Sci. 1996;21(1): 15-20.

3. Blitzer A, Brin MF, Keen MS, Aviv JE. Botulinum toxin for the treatment of hyperfunctional lines of the face. Arch Otolaryngol Head Neck Surg. 1993;119(9):1018-22.

4. Borodic GE. Botulinum A toxin for (expressionistic) ptosis overcorrection after frontalis sling. Ophthalmic Plast Reconstr Surg. 1992;8(2):137-42.

5. Carruthers A, Carruthers J. Clinical indications and injection technique for the cosmetic use of botulinum A exotoxin. Dermatol Surg. 1998;24(11): 1189-94.

6. Carruthers A, Carruthers J. Eyebrow height after botulinum toxin type A to the glabella. Dermatol Surg. 2007;33(1 Spec No.):S26-31.

7. Carruthers J, Stubbs HA. Botulinum toxin for benign essential blepharospasm, hemifacial spasm and age-related lower eyelid entropion. Can J Neurol Sci. 1987;14(1):42-5.

8. Flynn TC, Carruthers JA, Carruthers JA. BotulinumA toxin treatment of the lower eyelid improves infraorbital rhytides and widens the eye. Dermatol Surg. 2001;27(8):703-8.

9. Liew S, Dart A. Nonsurgical reshaping of the lower face. Aesthet Surg J. 2008;28(3):251-7.

10. Park MY, Ahn KY, Jung DS. Botulinum toxin type A treatment for contouring of the lower face. Dermatol Surg. 2003;29(5):477-83 (discussion 83).

11. To EW, Ahuja AT, Ho WS, et al. A prospective study of the effect of botulinum toxin A on masseteric muscle hypertrophy with ultrasonographic and electromyographic measurement. Br J Plast Surg. 2001;54(3):197-200.

12. von Lindern JJ, Niederhagen B, Appel T, Berge S, Reich RH. Type A botulinum toxin for the treatment of hypertrophy of the masseter and temporal muscles: an alternative treatment. Plast Reconstr Surg. 2001;107(2):327-32.

13. Brown EA, Schutz SG, Simpson DM. Botulinum toxin for neuropathic pain and spasticity: an overview. Pain Manag. 2014;4(2):129-51.

14. Castrillo Sanz A, Morollon Sanchez-Mateos N, Simonet Hernandez C, et al. Experience with botulinum toxin in chronic migraine. Neurologia. 2018;33(8):499-504.

15. de Almeida AR, Montagner S. Botulinum toxin for axillary hyperhidrosis. Dermatol Clin. 2014;32(4): 495-504.

16. Gracies JM, Brashear A, Jech R, et al. Safety and efficacy of abobotulinumtoxinA for hemiparesis in adults with upper limb spasticity after stroke or traumatic brain injury: a double-blind randomised controlled trial. Lancet Neurol. 2015;14(10): 992-1001.

17. Hara T, Abo M, Hara H, et al. Effects of botulinum toxin A therapy and multidisciplinary rehabilitation on upper and lower limb spasticity in poststroke patients. Int J Neurosci. 2017;127(6):469-78.

18. Hara T, Abo M, Hara H, et al. Effects of botulinum toxin A therapy and multidisciplinary rehabilitation on lower limb spasticity classified by spastic muscle echo intensity in post-stroke patients. Int J Neurosci. 2018;128(5):412-20.

19. Harris S, Rizzolo D. Botulinum toxin as a treatment for refractory overactive bladder. JAAPA. 2016;29(2):1-4.

20. Hsieh PF, Chiu HC, Chen KC, Chang CH, Chou EC. Botulinum toxin A for the treatment of overactive bladder. Toxins. 2016;8(3):59. 
21. Ramachandran R, Yaksh TL. Therapeutic use of botulinum toxin in migraine: mechanisms of action. Br J Pharmacol. 2014;171(18):4177-92.

22. Frevert J, Dressler D. Complexing proteins in botulinum toxin type A drugs: a help or a hindrance? Biologics. 2010;4:325-32.

23. Dressler D, Hallett M. Immunological aspects of botox, dysport and myobloc/neurobloc. Eur J Neurol. 2006;13(Suppl 1):11-5.

24. Greene P, Fahn S, Diamond B. Development of resistance to botulinum toxin type $\mathrm{A}$ in patients with torticollis. Mov Disord. 1994;9(2):213-7.

25. Srinoulprasert Y, Kantaviro W, Nokdhes YN, et al. Development of inhibition ELISA to detect antibody-induced failure of botulinum toxin a therapy in cosmetic indications. J Immunol Methods. 2019;473:112635.

26. Goschel H, Wohlfarth $\mathrm{K}$, Frevert J, Dengler R, Bigalke $\mathrm{H}$. Botulinum A toxin therapy: neutralizing and nonneutralizing antibodies-therapeutic consequences. Exp Neurol. 1997;147(1):96-102.

27. Pearce LB, Borodic GE, First ER, MacCallum RD. Measurement of botulinum toxin activity: evaluation of the lethality assay. Toxicol Appl Pharmacol. 1994;128(1):69-77.

28. Marion MH, Humberstone M, Grunewald R, Wimalaratna S. British neurotoxin network recommendations for managing cervical dystonia in patients with a poor response to botulinum toxin. Pract Neurol. 2016;16(4):288-95.

29. Chen F, Kuziemko GM, Stevens RC. Biophysical characterization of the stability of the 150-kilodalton botulinum toxin, the nontoxic component, and the 900-kilodalton botulinum toxin complex species. Infect Immun. 1998;66(6):2420-5.

30. Hefter H, Hartmann C, Kahlen U, Moll M, Bigalke $\mathrm{H}$. Prospective analysis of neutralising antibody titres in secondary non-responders under continuous treatment with a botulinumtoxin type A preparation free of complexing proteins-a single cohort 4-year follow-up study. BMJ Open. 2012;2(4):e000646.
31. Dressler D. New formulation of BOTOX. Complete antibody-induced therapy failure in hemifacial spasm. J Neurol. 2004;251(3):360.

32. Lee SK. Antibody-induced failure of botulinum toxin type A therapy in a patient with masseteric hypertrophy. Dermatol Surg. 2007;33(1 Spec No.): S105-S110110.

33. Bonaparte JP, Ellis D, Quinn JG, Rabski J, Hutton B. A comparative assessment of three formulations of botulinum toxin type A for facial rhytides: a systematic review with meta-analyses. Plast Reconstr Surg. 2016;137(4):1125-40.

34. Brown M, Nicholson G, Ardila MC, et al. Comparative evaluation of the potency and antigenicity of two distinct BoNT/A-derived formulations. J Neural Transm. 2013;120(2):291-8.

35. Kerscher M, Wanitphakdeedecha $\mathrm{R}$, Trindade de Almeida A, Maas C, Frevert J. IncobotulinumtoxinA: a highly purified and precisely manufactured botulinum neurotoxin type A. J Drugs Dermatol. 2019;18(1):52-7.

36. Evidente VG, Fernandez HH, LeDoux MS, et al. A randomized, double-blind study of repeated incobotulinumtoxinA (Xeomin $(\circledR))$ in cervical dystonia. J Neural Transm. 2013;120(12):1699-707.

37. Truong DD, Gollomp SM, Jankovic J, et al. Sustained efficacy and safety of repeated incobotulinumtoxinA (Xeomin $(\circledR))$ injections in blepharospasm. J Neural Transm. 2013;120(9): 1345-53. 